\title{
Life-long spontaneous exercise does not prolong lifespan but improves health span in mice
}

Rebeca Garcia-Valles', Mari Carmen Gomez-Cabrera', Leocadio Rodriguez-Mañas², Francisco J Garcia-Garcia ${ }^{3}$, Ana Diaz ${ }^{4}$ Inma Noguera ${ }^{4}$, Gloria Olaso-Gonzalez ${ }^{1}$ and Jose Viña ${ }^{1 *}$

\begin{abstract}
Background: Life expectancy at birth in the first world has increased from 35 years at the beginning of the 20th century to more than 80 years now. The increase in life expectancy has resulted in an increase in age-related diseases and larger numbers of frail and dependent people. The aim of our study was to determine whether life-long spontaneous aerobic exercise affects lifespan and healthspan in mice.

Results: Male C57BI/6J mice, individually caged, were randomly assigned to one of two groups: sedentary $(n=72)$ or spontaneous wheel-runners $(n=72)$. We evaluated longevity and several health parameters including grip strength, motor coordination, exercise capacity $\left(\mathrm{VO}_{2 \max }\right)$ and skeletal muscle mitochondrial biogenesis. We also measured the cortical levels of the brain-derived neurotrophic factor (BDNF), a neurotrophin associated with brain plasticity. In addition, we measured systemic oxidative stress (malondialdehyde and protein carbonyl plasma levels) and the expression and activity of two genes involved in antioxidant defense in the liver (that is, glutathione peroxidase (GPx) and manganese superoxide dismutase (Mn-SOD)). Genes that encode antioxidant enzymes are considered longevity genes because their over-expression may modulate lifespan. Aging was associated with an increase in oxidative stress biomarkers and in the activity of the antioxidant enzymes, GPx and Mn-SOD, in the liver in mice. Life-long spontaneous exercise did not prolong longevity but prevented several signs of frailty (that is, decrease in strength, endurance and motor coordination). This improvement was accompanied by a significant increase in the mitochondrial biogenesis in skeletal muscle and in the cortical BDNF levels.
\end{abstract}

Conclusion: Life-long spontaneous exercise does not prolong lifespan but improves healthspan in mice. Exercise is an intervention that delays age-associated frailty, enhances function and can be translated into the clinic.

Keywords: Longevity, Sarcopenia, BDNF, Successful aging, Mitochondria, Frailty

\section{Background}

World life expectancy has more than doubled over the past two centuries [1]. Life expectancy at birth in the first world has increased from 35 years at the beginning of the 20th century to more than 80 years now. Development of preventive medicine, improvements in nutrition and the use of antibiotics have probably been the main factors responsible for this important change which has been more pronounced in the last 100 years than in the previous 2,000. This transformation in the duration of life means that the number of older people

\footnotetext{
* Correspondence: jose.vina@uv.es

'Department of Physiology, Faculty of Medicine, University of Valencia, Fundacion Investigacion Hospital Clinico Universitario/INCLIVA, Av. Blasco Ibañez, 15, Valencia 46010, Spain

Full list of author information is available at the end of the article
}

has skyrocketed [2]. In developed countries, people over 65 years of age will represent $35 \%$ of the population by 2050. A concern of health providers is whether increasing longevity will increase disability, thus imposing an increasing financial burden [3]. Rather than extending lifespan we should be interested in an increased healthspan, the portion of the life span during which function is sufficient to maintain autonomy, control, independence, productivity and well-being [4]. Maximizing healthspan and preventing dysfunction are at least as important as extending lifespan $[4,5]$.

Limits to healthspan include disability, frailty, chronic diseases and, of course, lifespan [6]. Frailty is a geriatric syndrome, defined by the presence of three or more of the following criteria: unintentional weight loss, selfreported exhaustion, weakness, slow walking speed and 
low physical activity [7]. Thus, the maintenance of the neuromuscular function is critical in the prevention of frailty [8]. Interest in this syndrome has been growing over the last decade because frailty is the main risk factor for disability in older people and it also forewarns of other adverse outcomes, such as falls, hospitalization and death [7,9]. In fact, the European Union has recently launched an effort to reach a consensual clinical definition of frailty (FOD-CC. Health.2010.2.2.2-5). Frailty results from age-related cumulative declines across multiple physiological systems, leading to impaired homeostatic reserve and a reduced capacity of the organism to withstand stress, thus increasing vulnerability to adverse health outcomes. Physical exercise is a very promising intervention for the modulation of both healthspan and lifespan in a number of species [10-12]. The benefits of regular exercise go beyond longevity [10]. Life-long physical exercise has become one of the key strategies in the prevention and treatment of chronic, degenerative diseases among older people. In animals, physical activity by means of spontaneous wheel-running confers cardiovascular, metabolic and psychological benefits [13,14].

Thus, the primary aim of our study was to develop an intervention (that is, spontaneous exercise) that could increase survival but that could also enhance function, delay frailty and be easily translated into the clinic. Due to the current lack of a test for frailty in rodents we performed four different physiological measurements: grip strength, motor coordination, exercise capacity and skeletal muscle mitochondrial biogenesis, which have been linked to clinically relevant age-related frailty. We also evaluated brain-derived neurotrophic factor (BDNF) as an indicator of brain plasticity, in addition to oxidative stress markers (malondialdehyde and carbonylated protein plasma levels) and the expression and activity of two genes involved in the antioxidant defense (that is, glutathione peroxidase (GPx) and manganese superoxide dismutase (Mn-SOD).

\section{Results}

\section{Longevity curve and running wheel activity}

Figure 1 shows the effect of lifelong spontaneous exercise on longevity in mice. Exercise does not cause an increase in either average lifespan or maximal lifespan. Maximal lifespan was defined as the age at which the longer-lived animal died. In our mice it was 950 days. Average lifespan was defined as the age at which $50 \%$ of the animals died. It was 750 days for sedentary mice and 770 for wheel-runners $(P=0.09)$. Our mice ran an average of $4.6 \pm 1.5 \mathrm{~km} \cdot \mathrm{d}^{-1}$ at the beginning of the experiment. As in previous studies, there was a progressive decline in the distance run by the mice with advancing age $[10,15]$. Seventeen month-old mice ran approximately $0.5 \mathrm{~km} \cdot \mathrm{d}^{-1}$ and, as expected, this distance

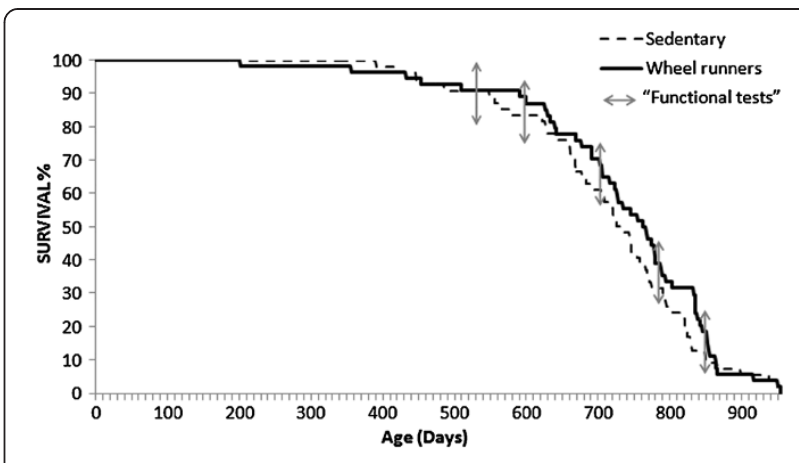

Figure 1 Survival curves of cohorts of sedentary $(n=72)$ and spontaneous wheel-running mice $(\mathbf{n}=\mathbf{7 2})$. The Kaplan-Meier representation of the two groups is shown. The median lifespan of the sedentary group was 750 days and it was 770 days in the wheel-runners. Maximal lifespan in both groups was 950 days. The functional tests were performed at different survival time points $(3,17,20,23,26$, and 29 months old) as shown by arrows in the longevity curve.

declined steadily during the life of the animals to the point that the very old ones (29 months and older) ran less than $0.1 \mathrm{~km} \cdot \mathrm{d}^{-1}$.

\section{Grip strength}

Loss of grip strength is strongly associated with increasing chronological age [16] and it appears to be a powerful index of frailty. Lower grip strength is associated with incident as well as prevalent disability, suggesting that age-related loss of muscle mass and volitional muscle strength can be a cause, as well as a consequence, of physical disability [17]. We found a progressive decline in grip strength as the animals grew older in both the sedentary and the active mice. However, those mice that had free access to the running wheel had significantly higher grip strength values $(P<0.01)$ than the sedentary ones at 17, 20, 23, and 26 months of age (See Figure 2, Panel A). Initial analysis for grip strength (month 3) indicated no difference between the groups.

\section{Motor coordination}

Neuromuscular coordination declines with aging [18]. The tightrope test, which we have used in the past $[19,20]$, is a widely used and well-validated behavioral marker of aging [21]. Neuromuscular coordination was estimated by quantifying the percentage of mice that successfully passed the tightrope test and was considered as a good marker of a decrease in physical and neuromuscular function (See Methods section for more details). Figure 2 (Panel B) shows that as age advances, the percentage of mice that did not pass the test increased in both groups, yet the spontaneous exercise group, with more passing members, had better results $(P<0.05)$ than the control group in the fourth and fifth periods tested (23 and 26 months of age). 


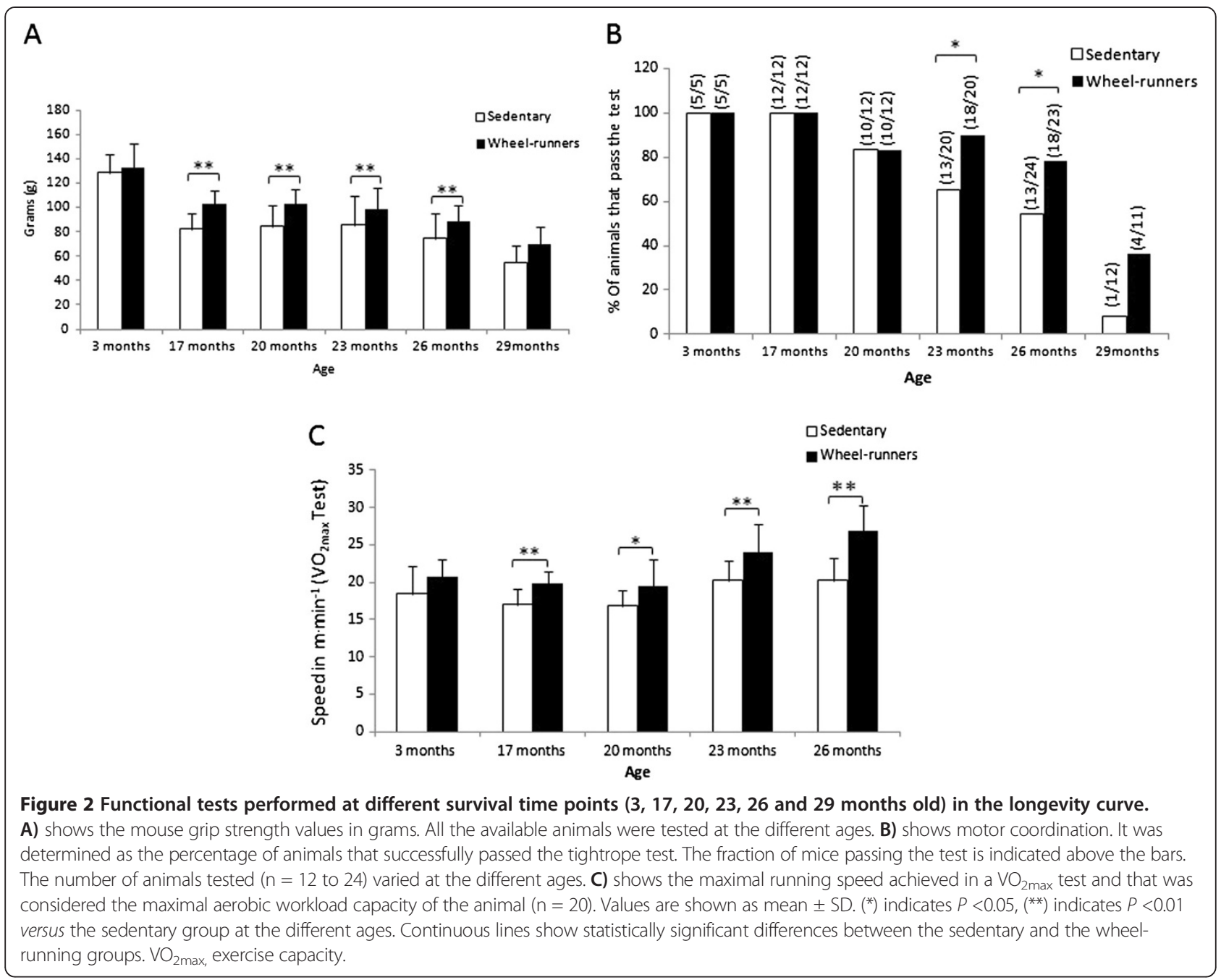

$\mathrm{VO}_{2 \max }$ test

Large-scale epidemiological studies of subjects with and without cardiovascular disease demonstrate that low aerobic exercise capacity $\left(\mathrm{VO}_{2 \max }\right)$ is a stronger predictor of mortality than other established risk factors, such as diabetes, smoking, body mass index (BMI) $>30$, hypertension and chronic obstructive pulmonary disease (COPD) [22-25]. There is a uniform rate of decline in $\mathrm{VO}_{2 \max }$ with age [26] and poor endurance has been considered as one of the five criteria to define frailty [7]. We found a significant difference in $\mathrm{VO}_{2 \max }$ between the runners and the sedentary animals in the test performed at the different survival time points (Figure 2, Panel C). The spontaneous wheel-running mice showed a significant increase in the maximal speed at which $\mathrm{VO}_{2 \max }$ was attained at 17, 20, 23 and 26 months of age. Initial analysis of $\mathrm{VO}_{2 \max }$ (month 3) indicated no difference between the groups.

\section{Mitochondrial biogenesis in skeletal muscle}

Aging causes a decrease in mitochondrial content and activity [27-29]. Figure 3 (Panel A) shows that there was a decrease $(P<0.01)$ in the protein levels of Peroxisome Proliferator-Activated Receptor- $\gamma$ Coactivator $1 \alpha$ $(\mathrm{PGC}-1 \alpha)$ in skeletal muscle during aging in the sedentary animals. However, spontaneous wheel-runners maintained, or even increased, their PGC- $1 \alpha$ levels $(P<0.05)$.

Mitochondrial content was estimated measuring cytochrome $C$ protein levels in skeletal muscle [30]. Exercise caused a significant increase $(P<0.05)$ in mitochondrial content, especially in the later stages of life, that is, when mitochondria become more critical to preventing ageassociated energy decay (See Figure 3, Panel B).

\section{Oxidative stress and antioxidant enzymes}

We did not find any change in plasma protein oxidation (Figure 4, Panel A). However, we found a significant 


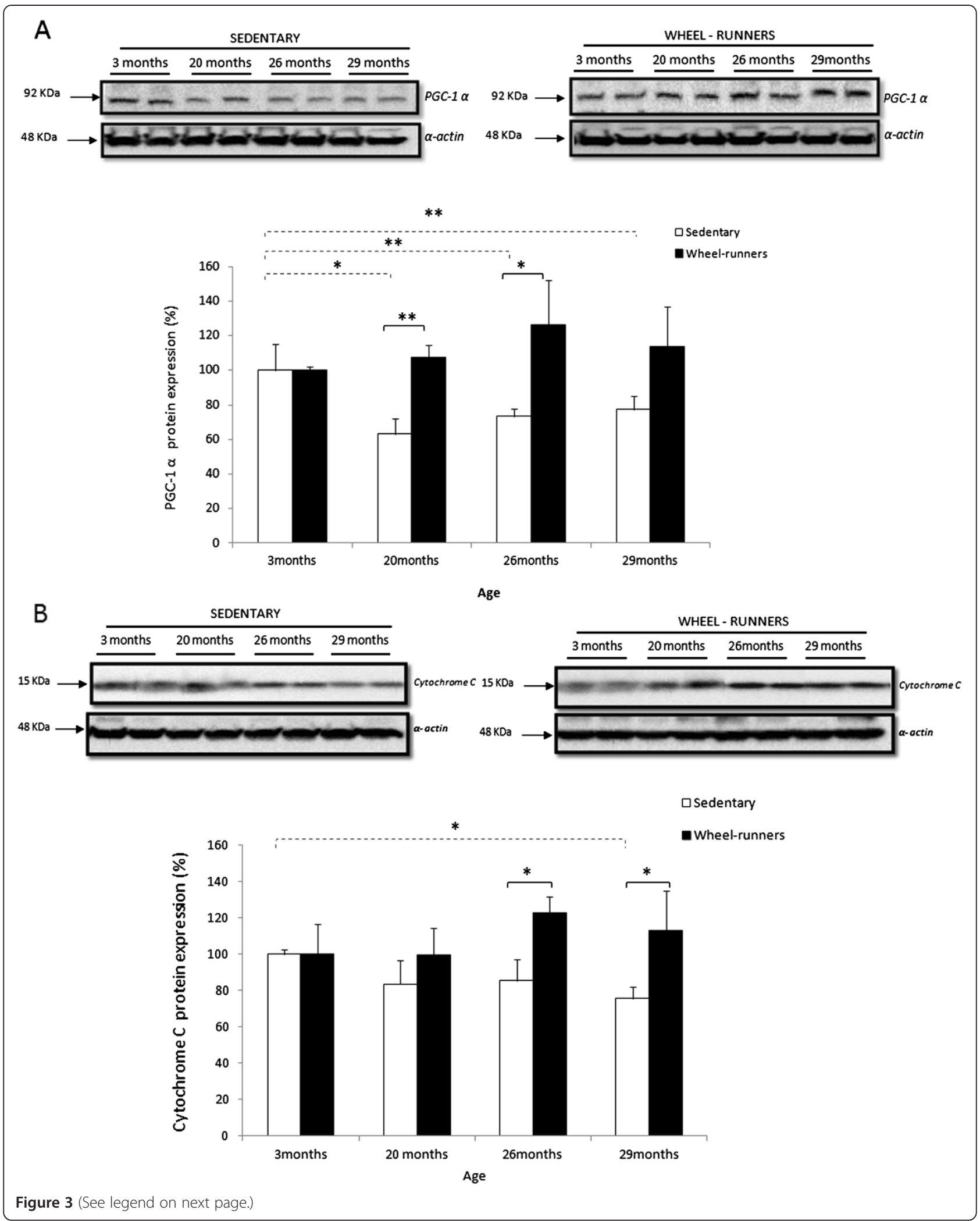


(See figure on previous page.)

Figure 3 Exercise-induced activation of the mitochondrial biogenesis pathway in mice skeletal muscle during aging. Western blotting analysis to detect (A) Peroxisome Proliferator-Activated Receptor- $\gamma$ Coactivator 1a (PGC-1a) and (B) cytochrome $C$ at different survival time points. Representative blots are shown. For the densitometric analysis of the results, values are shown as mean $( \pm$ SD). The content of $a$-actin, a housekeeping protein marker in skeletal muscle, was determined in all the experimental groups. $\left(^{*}\right)$ indicates $P<0.05,(* *)$ indicates $P<0.01$ versus the sedentary group at different ages. Values were normalized to those observed in the samples obtained from the three-month-old group, which was assigned a value of $100 \%$. Continuous lines show statistically significant differences between the sedentary and the wheel-running groups. The discontinuous lines show statistically significant differences between the periods studied in the sedentary group.

increase $(P<0.01)$ in plasma lipid peroxidation (determined as malondialdehyde (MDA)) in both the sedentary and the active animals as they aged (See Figure 4, Panel B). The MDA plasma levels at 29 months of age were twice those found in the 3-month-old animals, independent of the experimental group. Thus, spontaneous wheel-running did not prevent the aging-associated increase in oxidative stress.

We also determined the expression and the activity of the antioxidant enzymes MnSOD and GPx. We found no major changes in the mRNA levels of the enzymes
(See Figure 5, Panels A and C). However, their activity was elevated in the livers of the animals as they grew older (See Figure 5, Panels B and D).

\section{Cortical BDNF}

Protein levels of BDNF were quantified in the cortex of the animals by ELISA. We found a significant increase in the neurotrophin in the active animals. Thus, spontaneous wheel-running significantly prevented the age-associated fall in BDNF in mice 20- and 26months old.

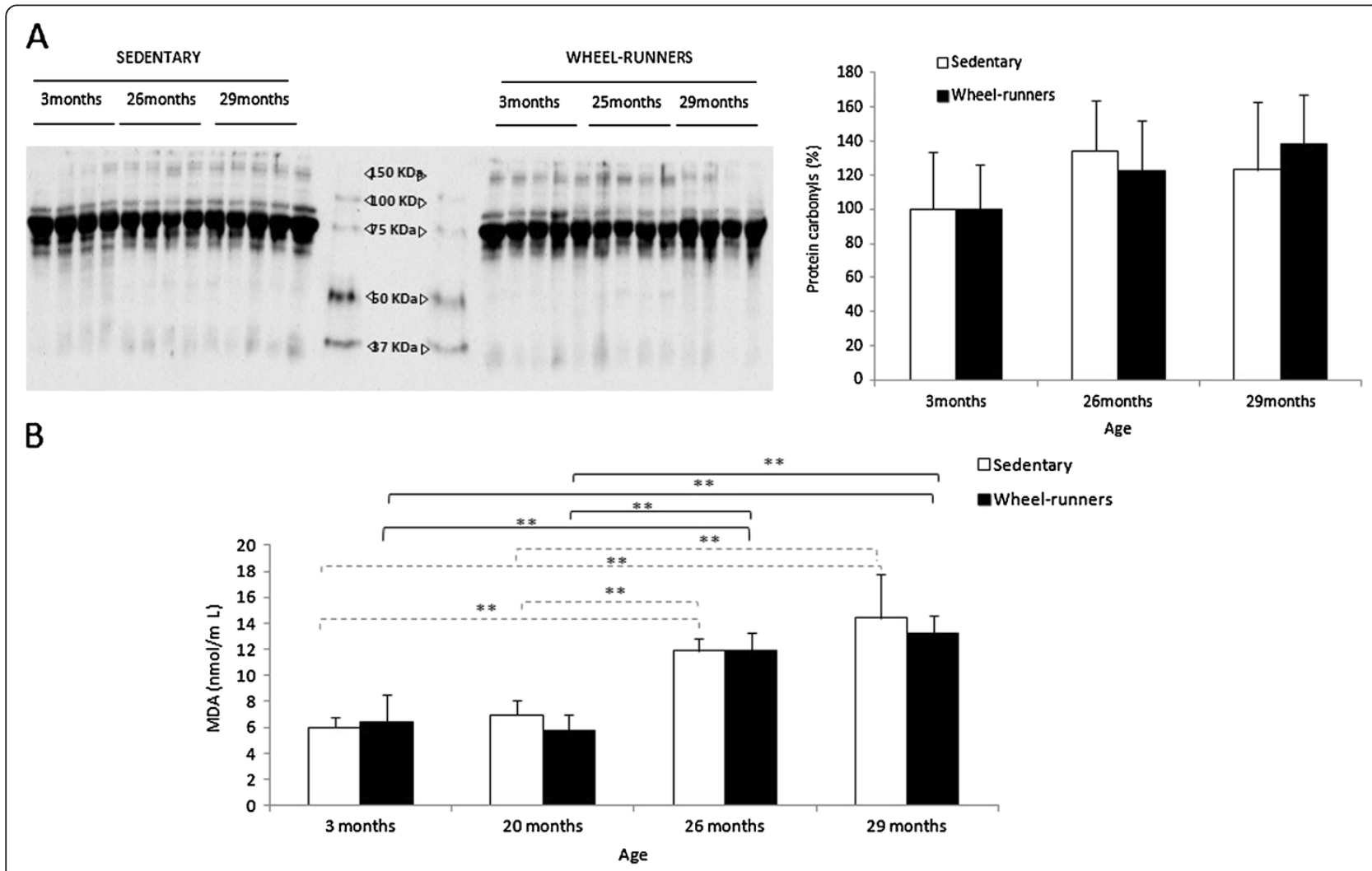

Figure 4 Plasma oxidative stress biomarkers at different survival time points (3, 20, 26 and 29 months old) in the longevity curve. A) shows a representative Western blot and the densitometric quantification of protein carbonyls in plasma. Values were normalized to those observed in the samples obtained from the three-month-old group, which was assigned a value of $100 \%$. B) shows plasma lipid peroxidation determined as malondialdehyde \{MDA). Values are shown as mean \pm SD. (*) indicates $P<0.05$, (**) indicates $P<0.01$. Continuous lines show statistically significant differences between the wheel-running animals. Discontinuous lines show statistically significant differences between the sedentary animals. 


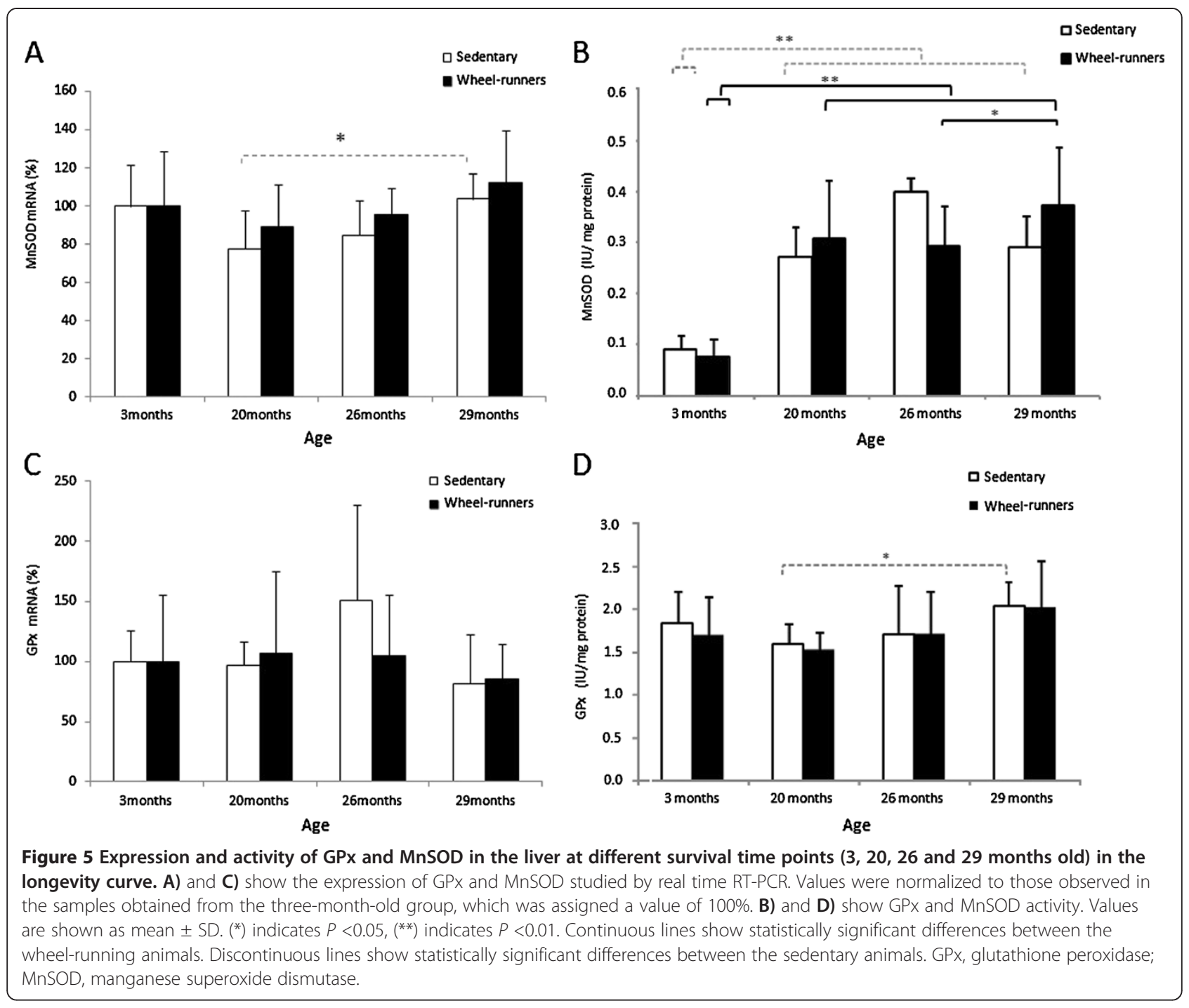

\section{Discussion}

Most of the interventions devised to understand the mechanisms of aging have been focused on survival [4]. Recently, however, emphasis has been placed on preventing disability (healthspan) and its predictors (frailty) rather that on merely increasing longevity (lifespan).

We have recently proposed that 'exercise acts as a drug' [31]. The beneficial effects of regular exercise for the promotion of health and cure of diseases have been clearly established in humans [11,32-34] as well as in rodents $[12,35,36]$. We did not find any effect of lifelong spontaneous exercise on longevity (See Figure 1). Exercise has been unequivocally associated with a slowing of age-specific mortality increases in rats and with an increased median lifespan [36]. However, the results in mice are not that clear. In 1984, it was shown that no significant differences in lifespan were found in mice that had free access to running-wheels during senescence and/or maturity [37]. In 2004, it was shown that moderate exercise, provided by weekly treadmill training (10, 15, and $20 \mathrm{~cm} . \mathrm{s}^{-1}$ for 5 minutes each, every 7 days) starting at 28 wks of age, increased survival in CD-1 mice (median lifespan was increased by $19 \%$ and maximal lifespan was increased by $15 \%$ to $21 \%$ in males) [12]. On the contrary, we did not find a significant difference on average or maximal lifespan in the wheel-running group, although a statistical trend $(P=0.09)$ was found. These different findings may be explained by the different experimental conditions. Essentially, we housed our mice in a clean animal house and we did not force the animals to exercise. Moreover, we used C57BL/6J mice (which do not gain weight with age) whereas CD-1 mice and Wistar rats do. We believe that C57BL/6J mice are more suitable for studying exercise and aging because the effects are free from the confounding factor of the exercise-induced loss of weight that may occur in animals that become obese with aging. In 2003, Bronikovski and co-workers, using lines of 
outbred genetically heterogeneous mice selectively bred for high spontaneous exercise, found that exercise increased median (17\%), but not maximum, lifespan in rodents [38]. In this case, differences not only in the strain but in the number of kilometers run per day between their animals and ours could explain these differences. These authors reported an average of $4.8 \mathrm{~km}^{\mathrm{day}}{ }^{-1}$ in 20-month-old animals while in our experiment the animals ran $1 \mathrm{~km} \cdot$ day $^{-1}$ at the same age.

We chose the C57BL/6J mouse as the strain for our model for three main reasons. First, this strain has been shown to perform well in spontaneous exercise studies [39]. Second, by using an inbred strain, we intended that all animals would begin with a nearly identical genotype (99.9\% genetically identical), thereby increasing the probability that any phenotypic variation would be strictly due to environmental influences. Finally, (unlike rats or humans) $\mathrm{C} 57 \mathrm{BL} / 6 \mathrm{~J}$ mice do not gain weight as they age and exercise does not cause a weight loss in these animals. Thus, because the level of spontaneous exercise was the only known variable between groups, any differences would be related to spontaneous exercise.

To support our results we determined oxidative stress parameters and the activity of the antioxidant enzymes in our study. The free radical theory of aging is one of the most prominent theories to explain aging. This theory, although recently questioned [40], has been tested in various laboratories and there are many published papers in its support [41]. As expected, we found a significant increase in plasma lipid peroxidation in the old animals, in both the active and inactive groups (See Figure 4). We also wanted to study the antioxidant status by measuring the expression and activity of the antioxidant enzymes MnSOD and GPx. Genes that encode antioxidant enzymes are considered longevity genes because their over-expression may modulate lifespan [42]. We found a significant increase in antioxidant enzyme activities (especially in MnSOD) as the animals grew older, independent of their physical activity (See Figure 5, Panels B and D). It has been well documented that several tissues increase their antioxidant enzyme activities as they age $[43,44]$. However, we did not find any significant changes in the relative abundance of mRNA for the enzymes (See Figure 5, Panels A and C). Our results suggest that age-related increases in MnSOD and GPx activity were not caused by enhanced gene expression but by a posttranslational modification (activation) of the enzyme molecules in aged liver [45].

The negative results in terms of lifespan led us to focus our study on healthspan. Ignatz Nascher, who coined the term 'geriatrics' and who founded this clinical field in the US, described the concept of healthspan (without using the term) as a goal of being productive and happy for an individual's entire lifespan, rather than seeking longevity despite severely hindering impairments of body and mind [2,46].

Frailty is a geriatric syndrome with a tremendous impact on the older individual, their family, and society as a whole. The components of frailty are a mixture of physiological, psychological, social and environmental factors (for example, sarcopenia, functional impairment, cognitive impairment, and depression). Physical exercise may affect all these factors. Thus, we aimed to determine whether life-long spontaneous exercise was a good strategy to prevent frailty in a mouse model. Our major problem was the lack of a test for frailty in experimental animals. Although the clinical interest in frailty has grown in recent years [47], research in experimental animal models of frailty is very rare. The most commonly used test for frailty is that of Linda Fried and co-workers [7]. They concluded that frailty is a combination of five components: unintentional weight loss, exhaustion, weakness, slow running speed and a decrease in physical activity. Based on this work, three functional tests were performed on our mice at six different survival time points (See Figure 2). We found that as the animals grew older, they showed poorer results in the tests that determined healthspan: grip strength (Panel A), motor coordination (Panel B) and aerobic exercise capacity (Panel C). Mice that had free access to running wheels performed significantly better than the sedentary animals in all the tests.

The beneficial effects of exercise on cognitive [48] and skeletal muscle function may be mediated by two adaptations: increased expression of neurotrophic factors in some brain areas [49] and the induction of mitochondrial biogenesis in skeletal muscle [50]. BDNF is a neurotrophic factor that may play an important role in old-age survival, because of its role in preventing neuronal death during stress [51] and in synaptic plasticity [52]. Plasma concentrations of BDNF are significantly higher in non-frail than in pre-frail women [52]. We observed that BDNF levels fall with age in sedentary animals but, remarkably, they increase with exercise in old animals and only fall in very old ones (that is, 29 months old) (See Figure 6).

A functional muscle that has not lost the capacity to synthesize healthy mitochondria is an important contributor in the prevention of frailty $[47,53]$. Thus, we determined two relevant proteins involved in mitochondrial biogenesis in skeletal muscle, PGC- $1 \alpha$ and cytochrome C. We recently showed that aging causes a lack of response of PGC- $1 \alpha$ to various stimuli [29]. We hypothesized that lifelong spontaneous exercise could prevent the lack of reactivity of PGC- $1 \alpha$ in the aging muscle and this turned out to be the case (See Figure 3, Panel A). We estimated the mitochondrial content by measuring cytochrome $\mathrm{C}$ 


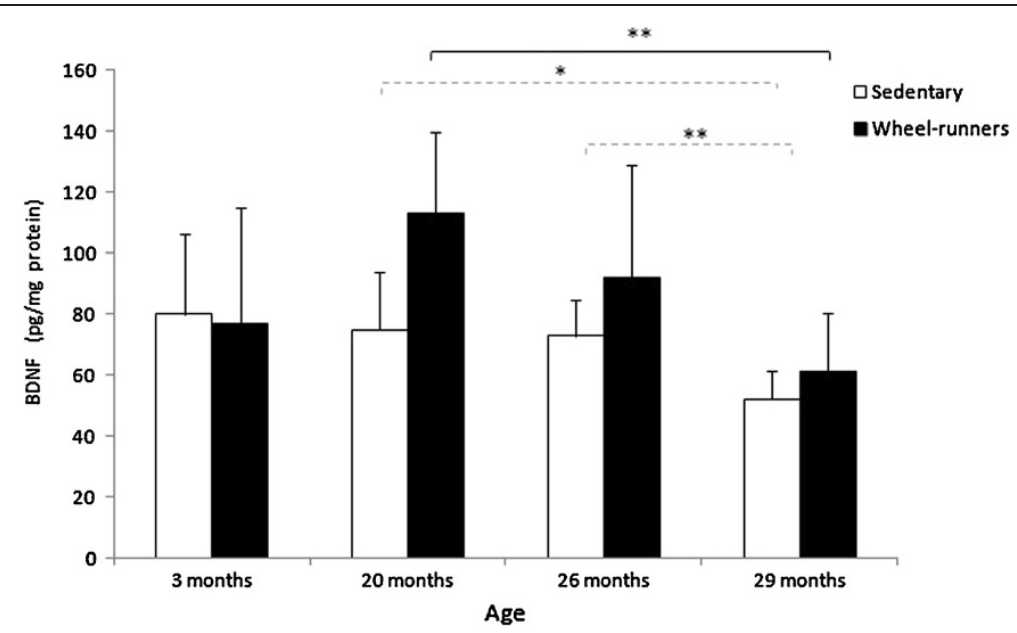

Figure 6 Cortex BDNF levels, determined by ELISA, in sedentary and wheel-running mice at different survival time points (3, 20, 26 and 29 months old) in the longevity curve. Values are shown as mean \pm SD. $\left(^{*}\right)$ indicates $P<0.05$, $\left(^{* *}\right)$ indicates $P<0.01$. Continuous lines show statistically significant differences between the wheel-running animals. Discontinuous lines show statistically significant differences between the sedentary animals. BDNF, brain-derived neurotrophic factor.

protein levels [30]. Spontaneous exercise resulted in a significantly higher level of this protein at 26 and 29 months of age when compared with the sedentary animals (See Figure 3, Panel B). PGC-1 $\alpha$ protects against skeletal muscle atrophy [54] and it is required for training-induced prevention of the age-associated decline in mitochondria [55]. Moreover, it has been recently shown that increased muscle PGC-1 $\alpha$ expression protects from sarcopenia and metabolic disease during aging [56]. Our results confirm that life-long spontaneous exercise contributes to the maintenance of the mitochondrial content in skeletal muscle during aging.

\section{Conclusion}

Lifelong spontaneous exercise does not prolong lifespan but improves healthspan in mice. Exercise is an intervention that enhances function and delays frailty in experimental animals. These results stress the importance of this intervention to prevent human frailty and dependency.

\section{Methods}

\section{Experimental animals}

Adult male C57BL/6J mice, three-months old, were randomly assigned to one of two groups: sedentary control $(n=72)$ or spontaneous exercise $(n=72)$. The animals were housed in individual cages. The mice in the exercise group had 24-hour access to a $11.5 \mathrm{~cm}$ diameter running wheel connected to an electronic wheel-revolution counter located at the top of the cage. The sedentary mice were free to move around their cage but did not have access to a running wheel. We chose to wait until three months of age to allow our animals access to exercise wheels, as this is the age at which mice reach musculoskeletal maturity, and we estimated that our animals would achieve maximal performance if they were exposed to running wheels at this age [57].

The average temperature in the animal house was $23 \pm 1{ }^{\circ} \mathrm{C}$, relative humidity was $60 \%$, and 12 hour day/ night cycles were maintained. The mice were checked daily. Water and food were available ad libitum. Food consumption was determined weekly by subtracting the amount of food remaining from the amount offered. No differences between the sedentary and the wheel-runners were found (data not shown). The cage bottoms were cleaned once every fortnight and wheels once every four weeks.

The values obtained in the longevity curve were registered for as long as the experiment lasted, sacrificing four mice from each group at specific survival points: 3 , 20, 26 and 29 months of age, to obtain data for subsequent analysis. Liver, skeletal muscle and brain were immediately dissected and stored at $-80^{\circ} \mathrm{C}$ for further analysis.

The experimental protocol was approved by the Committee of Ethics in Research of the Faculty of Medicine, University of Valencia.

\section{Wheel running activity}

The activity of the mice on the running wheels was monitored by a magnetic switch affixed to each wheel, which recorded the number of revolutions completed. 
Physical activity was recorded continuously and added up each week for analysis. Free open-field locomotor activity of mice within cages was not measured.

\section{Motor coordination test (tight-rope test)}

The tight-rope test was based on the method previously described by Miquel [21] and extensively used by our team [19]. Mice were placed in the middle of a $60 \mathrm{~cm}$ long and $1.5 \mathrm{~cm}$ wide rope. The test results were considered successful if the mouse reached either the end of the rope or if it was able to stay on it for 60 seconds. All the animals had five chances to complete the test. We determined the percentage of mice that succeeded in passing the test. This test was performed at six different time points in the longevity curve $(3,17,20,23,26$ and 29 months of age).

\section{Incremental treadmill test $\left(\mathrm{VO}_{2 \max }\right.$ test)}

The animals were submitted to a graded intensity treadmill test (Model 1050 LS Exer3/6; Columbus Instruments, Columbus, OH, USA) to determine their endurance and 'slowness' along the longevity curve. We followed a modification of the protocol of Davidson and co-workers [58]. After the warm-up, the treadmill band velocity was increased until the animals were unable to run further. The initial bout of 6 minutes at $6 \mathrm{~m} . . \mathrm{min}^{-1}$ was followed by consecutive $2 \mathrm{~m} \cdot \mathrm{min}^{-1}$ increments every two minutes. Exhaustion was defined as the third time a mouse could no longer keep pace with the speed of the treadmill and remained on the shock grid for two seconds rather than running. Exercise motivation was provided for all rodents by means of an electronic shock grid at the treadmill rear. However, the electric shock was used sparingly during the test. The maximal running speed was considered the maximal aerobic workload capacity of the animal (22). This test was performed at five different time points in the longevity curve (3, 17, 20, 23 and 26 months of age). We could not perform the test when the animals were 29 months old because they ran less than $0.1 \mathrm{~km}$ daily.

\section{Grip strength test}

A grip strength meter (Panlab, Harvard Apparatus. Barcelone. Spain) was employed in assessing neuromuscular function by sensing the peak amount of force that the mice applied in grasping specially designed pull bar assemblies. Metering was performed with precision force gauges in such a manner as to retain the peak force applied on a digital display. Mice were randomly chosen to grasp the pull-bar with their forelimb for a few seconds. The animals were then drawn along a straight line leading away from the sensor. The animals released at some point and the maximum force attained was stored on the display. Peak force was automatically registered in grams-force by the apparatus. Data were recorded, and four additional trials were immediately given [59]. This test was performed at six different time points in the longevity curve $(3,17,20,23,26$ and 29 months of age).

\section{SDS-PAGE and western blotting}

Aliquots of muscle lysate were separated by SDS-PAGE. Proteins were then transferred to nitrocellulose membranes, which were incubated overnight at $4^{\circ} \mathrm{C}$ with appropriate primary antibodies: anti-PGC-1 $\alpha$ (1:1000, Cayman. Ann Arbor. Michigan. USA), anti-cytochrome C (1:1000, Santa Cruz Biotechnology Inc. Dallas. Texas. USA), and anti- $\alpha$-actin (1:700, Sigma Aldrich. St. Louis. Missouri. USA). Thereafter, membranes were incubated with a secondary antibody for one hour at room temperature. Specific proteins were visualized by using the enhanced chemiluminescence procedure, as specified by the manufacturer (Amersham Biosciences, Piscataway, NJ, USA). Autoradiographic signals were assessed by using a scanning densitometer (BioRad, Hercules, CA, USA). The densitometry analysis was carried out immediately before saturation of the immunosignal. Data were represented as arbitrary units of immunostaining. To check for differences in loading and transfer efficiency across membranes, an antibody directed against $\alpha$-actin was used to hybridize with all the membranes previously incubated with the respective antibodies.

\section{Determination of plasma MDA and protein carbonyls}

MDA was determined in plasma by an HPLC method as described in [60]. Oxidative modification of total proteins was assessed by immunoblot detection of protein carbonyl groups using the 'OxyBlot' protein oxidation kit (Millipore. Madrid. Spain) following the manufacturer's instructions. Approximately $20 \mu \mathrm{g}$ of total protein was loaded onto paired gels and electrophoretically separated (see previous section). Antibody antidinitrophenylhydrazone was purchased from Intergen. The procedure to quantify total protein carbonyls with the OxyBlot kit used densitometry of the oxyblot and of the Ponceau staining, followed by finding the ratio between the total density in the oxyblot and the total density in the Ponceau [19].

\section{RNA isolation, reverse transcription and PCR}

Total RNA was extracted from liver tissue with Trizol ${ }^{\mathrm{mi}}$ (Invitrogen. Madrid. Spain) according to the manufacturer's protocol. The purity of the samples was assessed by determining the $260 \mathrm{~nm} / 280 \mathrm{~nm}$ ratio, which was always above 1.9, and total RNA was quantified from the absorbance at $260 \mathrm{~nm}$. We synthesized cDNA from $1 \mu \mathrm{g}$ of RNA using random hexamer primers and the High Capacity cDNA Reverse Transcription Kit (Applied Biosystems, Madrid, Spain). Reverse transcription 
conditions comprised an initial incubation step at $25^{\circ} \mathrm{C}$ for 10 minutes to allow random hexamers to anneal, followed by cDNA synthesis at $37^{\circ} \mathrm{C}$ for 120 minutes and the final inactivation step for 5 minutes at $95^{\circ} \mathrm{C}$. Real-time PCR was performed with an ABI 7900 sequence-detection system (Applied Biosystems). Primers for amplifying specific fragments of the genes were obtained from Thermo Fisher Scientific GmbH (Ulm, Germany). Real-time PCR was performed in duplicate in a total reaction volume of $20 \mu \mathrm{L}$ using Maxima ${ }^{\mathrm{Tm}}$ SYBR green/ROX qPCR Master Mix (Fermentas, Madrid, Spain). The thermal cycling protocol was as follows: initial denaturation for 10 minutes at $95^{\circ} \mathrm{C}$ followed by 40 cycles of 10 seconds at $95^{\circ} \mathrm{C}, 10$ seconds at $62^{\circ} \mathrm{C}$, and 10 seconds at $72^{\circ} \mathrm{C}$. The fluorescence signal was measured at the end of each extension step at $72^{\circ} \mathrm{C}$. At the end of each reaction, a melting curve analysis was performed to confirm that only the specific products were amplified. The threshold cycle $(\mathrm{Ct})$ was converted to a relative gene expression by the use of a standard curve. For each sample, the expression of the target gene mRNA was normalized with the GAPDH mRNA content. The specific primers used for GPx were: 5'-GAC ATC AGG AGA ATG GCA AG-3' (forward) and 5'- CAT CAC CAA GCC AAT ACC AC-3' (reverse); for MnSOD they were: 5'-CGT GCT CCC ACA CAT CAA TG-3' (forward) and 5'-TGA ACG TCA CCG AGG AGA AG-3' (reverse); and for the housekeeping gene GAPDH they were: 5'- CCT GGA GAA ACC TGC CAA GTA TG-3' (forward) and 5'GGT CCT CAG TGT AGC CCA AGA TG-3' (reverse).

\section{Enzyme activities}

GPx activity was measured as described by Flohe et al. [61]. SOD was determined following the instructions of the 'Superoxide Dismutase Assay Kit' (Caymen Chemical).

\section{ELISA analysis}

Protein levels of BDNF were quantified in the cortex by ELISA (CYT306 Millipore, Bedford, MA, USA), following the manufacturer's instructions. The samples were measured at $450 \mathrm{~nm}$ using a plate reader (iEMS Reader MF; Labsystems, Vantaa, Finland).

\section{Data analysis}

Mean values and standard deviation were considered for descriptive statistics. To estimate lifespan differences between groups, a Kaplan-Meier curve was performed. Differences in maximal running time and speed, grip strength test and motor coordination were tested using Fisher's exact test for each age group and parameter. To determine the effect of spontaneous exercise on BDNF, PGC- $1 \alpha$ and cytochome $\mathrm{C}$ protein expression in skeletal muscle we performed a twotailed Student's t-test for unpaired samples. Differences were considered significant at $P<0.05$. Statistical calculations were performed using SPSS (version Pasw Statistics 17.0) software.

\section{Abbreviations}

BDNF: Brain-derived neurotrophic factor; ELISA: Enzyme-linked immunosorbent assay; GPx: Glutathione peroxidase; HPLC: High performance liquid chromatography; MDA: Malondialdehyde; Mn-SOD: Manganese superoxide dismutase; PCR: Polymerase chain reaction; $V_{2}$ max: exercise capacity.

\section{Competing interests}

The authors declare that they have no competing interests.

\section{Authors' contributions}

RG-V and GO-G performed the experimental work; MCG-C, FJG-G and LR-M analyzed data and assisted in editing and writing the paper; DA, and NI supervised all the animal work and designed research; and J $V$ wrote the paper and directed the project. All authors read and approved the final manuscript.

\section{Acknowledgements}

We thank Mrs Marilyn Noyes for her kind help in reviewing the manuscript. This work was supported by grants SAF2010-19498,from the Spanish Ministry of Education and Science (MEC); ISCIII2006-RED13-027 from the Red Temática de investigación cooperativa en envejecimiento y fragilidad (RETICEF); P2011/02 RM Cátedra Real Madrid-UEM; PROMETEO2010/074 from 'Conselleria de Sanitat de la Generalitat Valenciana'; 35NEURO GentxGent from 'Fundació Gent Per Gent de la Comunitat Valenciana'; PI11/01068 del ISCIII, and EU Funded COSTB35 and CM1001. This study has been co-financed by FEDER funds from the European Union.

\section{Author details}

${ }^{1}$ Department of Physiology, Faculty of Medicine, University of Valencia, Fundacion Investigacion Hospital Clinico Universitario/INCLIVA, Av. Blasco Ibañez, 15, Valencia 46010, Spain. ${ }^{2}$ Red Temática de Investigación Cooperativa en Envejecimiento y Fragilidad (RETICEF), Instituto de Salud Carlos III, Servicio de Geriatría, Hospital Universitario de Getafe, Ministerio de Sanidad y Consumo, Madrid, Spain. ${ }^{3}$ Virgen del Valle Geriatric Hospital, Toledo, Spain. ${ }^{4}$ UCIM, University of Valencia, Valencia, Spain.

Received: 10 May 2013 Accepted: 5 August 2013

Published: 16 September 2013

\section{References}

1. Oeppen J, Vaupel JW: Demography. Broken limits to life expectancy. Science 2002, 296:1029-1031.

2. Goetzl EJ: Is aging a drug target? FASEB J 2011, 25:2509-2511.

3. Fries JF: Aging, natural death, and the compression of morbidity. N EnglJ Med 1980, 303:130-135.

4. Kirkland $J \mathrm{~L}$, Peterson C: Healthspan, translation, and new outcomes for animal studies of aging. J Gerontol A Biol Sci Med Sci 2009, 64:209-212.

5. Tatar M: Can we develop genetically tractable models to assess healthspan (rather than life span) in animal models? J Gerontol A Biol Sci Med Sci 2009, 64:161-163.

6. Kirkland JL: Translating advances from the basic biology of aging into clinical application. Exp Gerontol 2013, 48:1-5.

7. Fried LP, Tangen CM, Walston J, Newman AB, Hirsch C, Gottdiener J, Seeman T, Tracy R, Kop WJ, Burke G, McBurnie MA: Frailty in older adults: evidence for a phenotype. J Gerontol A Biol Sci Med Sci 2001, 56:M146-M156.

8. Pendergast DR, Fisher NM, Calkins E: Cardiovascular, neuromuscular, and metabolic alterations with age leading to frailty. J Gerontol 1993, 48(Spec No):61-67.

9. Ensrud KE, Ewing SK, Cawthon PM, Fink HA, Taylor BC, Cauley JA, Dam TT, Marshall LM, Orwoll ES, Cummings SR: A comparison of frailty indexes for the prediction of falls, disability, fractures, and mortality in older men. J Am Geriatr Soc 2009, 57:492-498.

10. Holloszy JO: Longevity of exercising male rats: effect of an antioxidant supplemented diet. Mech Ageing Dev 1998, 100:211-219.

11. Morris JN, Heady JA, Raffle PA, Roberts CG, Parks JW: Coronary heart-disease and physical activity of work. Lancet 1953, 265:1053-1057. 
12. Navarro A, Gomez C, Lopez-Cepero JM, Boveris A: Beneficial effects of moderate exercise on mice aging: survival, behavior, oxidative stress, and mitochondrial electron transfer. Am J Physiol Regul Integr Comp Physiol 2004, 286:R505-R511.

13. Gielen $\mathrm{S}$, Schuler $\mathrm{G}$, Hambrecht R: Exercise training in coronary artery disease and coronary vasomotion. Circulation 2001, 103:E1-E6.

14. Greenwood BN, Foley TE, Day HE, Campisi J, Hammack SH, Campeau S, Maier SF, Fleshner M: Freewheel running prevents learned helplessness/ behavioral depression: role of dorsal raphe serotonergic neurons. J Neurosci 2003, 23:2889-2898.

15. Figueiredo PA, Powers SK, Ferreira RM, Amado F, Appell HJ, Duarte JA: Impact of lifelong sedentary behavior on mitochondrial function of mice skeletal muscle. J Gerontol A Biol Sci Med Sci 2009, 64:927-939.

16. Bassey EJ, Harries UJ: Normal values for handgrip strength in 920 men and women aged over 65 years, and longitudinal changes over 4 years in 620 survivors. Clin Sci (Lond) 1993, 84:331-337.

17. Syddall $H$, Cooper C, Martin F, Briggs $R$, Aihie Sayer A: Is grip strength a useful single marker of frailty? Age Ageing 2003, 32:650-656.

18. Ingram DK, Reynolds MA: Assessing the predictive validity of psychomotor tests as measures of biological age in mice. Exp Aging Res 1986, 12:155-162.

19. Matheu A, Maraver A, Klatt P, Flores I, Garcia-Cao I, Borras C, Flores JM, Vina J, Blasco MA, Serrano M: Delayed ageing through damage protection by the Arf/p53 pathway. Nature 2007, 448:375-379.

20. Tomas-Loba A, Flores I, Fernandez-Marcos PJ, Cayuela ML, Maraver A, Tejera A, Borras C, Matheu A, Klatt P, Flores JM, Viña J, Serrano M, Blasco MA: Telomerase reverse transcriptase delays aging in cancer-resistant mice. Cell 2008, 135:609-622

21. Miquel J, Blasco M: A simple technique for evaluation of vitality loss in aging mice, by testing their muscular coordination and vigor. Exp Gerontol 1978, 13:389-396.

22. Myers J, Prakash M, Froelicher V, Do D, Partington S, Atwood JE: Exercise capacity and mortality among men referred for exercise testing. $N$ Engl J Med 2002, 346:793-801.

23. Yusuf S, Hawken S, Ounpuu S, Dans T, Avezum A, Lanas F, McQueen M, Budaj A, Pais P, Varigos J, Lisheng L: Effect of potentially modifiable risk factors associated with myocardial infarction in 52 countries (the INTERHEART study): case-control study. Lancet 2004, 364:937-952.

24. Kavanagh T, Mertens DJ, Shephard RJ, Beyene J, Kennedy J, Campbell R, Sawyer $P$, Yacoub M: Long-term cardiorespiratory results of exercise training following cardiac transplantation. Am J Cardiol 2003, 91:190-194.

25. Kavanagh T, Mertens DJ, Hamm LF, Beyene J, Kennedy J, Corey P, Shephard $\mathrm{RJ}$ : Prediction of long-term prognosis in 12169 men referred for cardiac rehabilitation. Circulation 2002, 106:666-671.

26. Buskirk ER, Hodgson JL: Age and aerobic power: the rate of change in men and women. Fed Proc 1987, 46:1824-1829.

27. Miquel J, Economos AC, Fleming J, Johnson JE Jr: Mitochondrial role in cell aging. Exp Gerontol 1980, 15:575-591.

28. Sastre J, Pallardo FV, Pla R, Pellin A, Juan G, O'Connor JE, Estrela JM, Miquel J, Vina J: Aging of the liver: age-associated mitochondrial damage in intact hepatocytes. Hepatology 1996, 24:1199-1205.

29. Derbre F, Gomez-Cabrera MC, Nascimento AL, Sanchis-Gomar F, Martinez-Bello VE, Tresguerres JA, Fuentes T, Gratas-Delamarche A, Monsalve M, Vina J: Age associated low mitochondrial biogenesis may be explained by lack of response of PGC-1alpha to exercise training. Age (Dordr) 2012, 34:669-679.

30. Gomez-Cabrera MC, Domenech E, Romagnoli M, Arduini A, Borras C, Pallardo FV, Sastre J, Vina J: Oral administration of vitamin $C$ decreases muscle mitochondrial biogenesis and hampers training-induced adaptations in endurance performance. Am J Clin Nutr 2008, 87:142-149.

31. Vina J, Sanchis-Gomar F, Martinez-Bello V, Gomez-Cabrera M: Exercise acts as a drug. Pharmacological benefits of exercise. Br J Pharmacol 2012, 167:1-12.

32. Karvonen MJ, Klemola H, Virkajarvi J, Kekkonen A: Longevity of endurance skiers. Med Sci Sports 1974, 6:49-51.

33. Paffenbarger RS Jr, Hyde RT, Wing AL, Lee IM, Jung DL, Kampert JB: The association of changes in physical-activity level and other lifestyle characteristics with mortality among men. N Engl J Med 1993, 328:538-545.
34. Sanchis-Gomar F, Olaso-Gonzalez G, Corella D, Gomez-Cabrera MC, Vina J: Increased average longevity among the "Tour de France" cyclists. Int J Sports Med 2011, 32:644-647.

35. Goodrick CL: Effects of long-term voluntary wheel exercise on male and female Wistar rats. I. Longevity, body weight, and metabolic rate. Gerontology 1980, 26:22-33.

36. Holloszy JO, Smith EK, Vining M, Adams S: Effect of voluntary exercise on longevity of rats. J Appl Physiol 1985, 59:826-831.

37. Samorajski T, Delaney C, Durham L, Ordy JM, Johnson JA, Dunlap WP: Effect of exercise on longevity, body weight, locomotor performance, and passive-avoidance memory of C57BL/6J mice. Neurobiol Aging 1985, 6:17-24.

38. Bronikowski AM, Carter PA, Morgan TJ, Garland T Jr, Ung N, Pugh TD, Weindruch $\mathrm{R}$, Prolla TA: Lifelong voluntary exercise in the mouse prevents age-related alterations in gene expression in the heart. Physiol Genomics 2003, 12:129-138.

39. Lerman I, Harrison BC, Freeman K, Hewett TE, Allen DL, Robbins J, Leinwand $L A$ : Genetic variability in forced and voluntary endurance exercise performance in seven inbred mouse strains. J Appl Physiol 2002, 92:2245-2255

40. Yang W, Hekimi S: A mitochondrial superoxide signal triggers increased longevity in Caenorhabditis elegans. PLoS Biol, 8:e1000556.

41. Gomez-Cabrera MC, Sanchis-Gomar F, Garcia-Valles R, Pareja-Galeano H, Gambini J, Borras C, Vina J: Mitochondria as sources and targets of damage in cellular aging. Clin Chem Lab Med 2012

50:1287-1295

42. Vina J, Gambini J, Lopez-Grueso R, Abdelaziz KM, Jove M, Borras C: Females live longer than males: role of oxidative stress. Curr Pharm Des 2011, 17:3959-3965

43. Ji LL: Exercise at old age: does it increase or alleviate oxidative stress? Ann N Y Acad Sci 2001, 928:236-247.

44. Wozniak A, Drewa G, Wozniak B, Schachtschabel DO: Activity of antioxidant enzymes and concentration of lipid peroxidation products in selected tissues of mice of different ages, both healthy and melanoma-bearing. Z Gerontol Geriatr 2004, 37:184-189.

45. Ji LL: Exercise-induced modulation of antioxidant defense. Ann N Y Acad Sci 2002, 959:82-92.

46. Nascher IL, Jacobi A: Geriatrics: the diseases of old age and their treatment including physiological old age, home and institutional care, and medico-legal relations. 2nd edition. Paul K, French, Trubner; 1919.

47. Gill TM, Gahbauer EA, Han L, Allore HG: Trajectories of disability in the last year of life. N Engl J Med 2010, 362:1173-1180.

48. Neeper SA, Gomez-Pinilla F, Choi J, Cotman C: Exercise and brain neurotrophins. Nature 1995, 373:109.

49. Neeper SA, Gomez-Pinilla F, Choi J, Cotman CW: Physical activity increases mRNA for brain-derived neurotrophic factor and nerve growth factor in rat brain. Brain Res 1996, 726:49-56

50. Holloszy JO: Biochemical adaptations in muscle. Effects of exercise on mitochondrial oxygen uptake and respiratory enzyme activity in skeletal muscle. J Biol Chem 1967, 242:2278-2282.

51. Schabitz WR, Steigleder T, Cooper-Kuhn CM, Schwab S, Sommer C, Schneider A, Kuhn HG: Intravenous brain-derived neurotrophic factor enhances poststroke sensorimotor recovery and stimulates neurogenesis. Stroke 2007, 38:2165-2172.

52. Coelho FM, Pereira DS, Lustosa LP, Silva JP, Dias JM, Dias RC, Queiroz BZ Teixeira AL, Teixeira MM, Pereira LS: Physical therapy intervention (PTI) increases plasma brain-derived neurotrophic factor (BDNF) levels in non-frail and pre-frail elderly women. Arch Gerontol Geriatr 2011, 54:415-420

53. Fiatarone MA, O'Neill EF, Ryan ND, Clements KM, Solares GR, Nelson ME, Roberts SB, Kehayias JJ, Lipsitz LA, Evans WJ: Exercise training and nutritional supplementation for physical frailty in very elderly people. $N$ Engl J Med 1994, 330:1769-1775.

54. Sandri M, Lin J, Handschin C, Yang W, Arany ZP, Lecker SH, Goldberg AL, Spiegelman BM: PGC-1alpha protects skeletal muscle from atrophy by suppressing FoxO3 action and atrophy-specific gene transcription. Proc Natl Acad Sci U S A 2006, 103:16260-16265.

55. Leick L, Lyngby SS, Wojtasewski JF, Pilegaard H: PGC-1alpha is required for training-induced prevention of age-associated decline in mitochondrial enzymes in mouse skeletal muscle. Exp Gerontol 2010, 45:336-342. 
56. Wenz T, Rossi SG, Rotundo RL, Spiegelman BM, Moraes CT: Increased muscle PGC-1alpha expression protects from sarcopenia and metabolic disease during aging. Proc Natl Acad Sci U S A 2009, 106:20405-20410.

57. Lapvetelainen T, Hyttinen MM, Saamanen AM, Langsjo T, Sahlman J, Felszeghy S, Vuorio E, Helminen HJ: Lifelong voluntary joint loading increases osteoarthritis in mice housing a deletion mutation in type II procollagen gene, and slightly also in non-transgenic mice. Ann Rheum Dis 2002, 61:810-817.

58. Davidson SR, Burnett M, Hoffman-Goetz L: Training effects in mice after long-term voluntary exercise. Med Sci Sports Exerc 2006, 38:250-255.

59. Crabbe JC, Cotnam CJ, Cameron AJ, Schlumbohm JP, Rhodes JS, Metten P, Wahlsten D: Strain differences in three measures of ethanol intoxication in mice: the screen, dowel and grip strength tests. Genes Brain Behav 2003, 2:201-213.

60. Young SHY, Knight JA, Hopfer SM, Zaharia O, Leach CN Jr, Sunderman FW $\mathrm{Jr}$ : Lipoperoxides in plasma as measured by liquid-chromatographic separation of malondialdehyde-thiobarbituric acid adduct. Clin Chem 1987, 33:214-220.

61. Flohe L, Gunzler WA: Assays of glutathione peroxidase. Methods Enzymol 1984, 105:114-121.

doi:10.1186/2046-2395-2-14

Cite this article as: Garcia-Valles et al.: Life-long spontaneous exercise does not prolong lifespan but improves health span in mice. Longevity \& Healthspan 2013 2:14.

\section{Submit your next manuscript to BioMed Central and take full advantage of:}

- Convenient online submission

- Thorough peer review

- No space constraints or color figure charges

- Immediate publication on acceptance

- Inclusion in PubMed, CAS, Scopus and Google Scholar

- Research which is freely available for redistribution 